\title{
Tissue Inhibitor of Metalloproteinase 1 to Creatinine Ratio Measurement
}

National Cancer Institute

\section{Source}

National Cancer Institute. Tissue Inhibitor of Metalloproteinase 1 to Creatinine Ratio

Measurement. NCl Thesaurus. Code C106575.

The determination of the ratio of tissue inhibitor of metalloproteinase 1 compared to creatinine present in a sample. The measurement may be expressed as a ratio or percentage. 